\title{
Technology of Integrated Impact on the Low-Permeable Reservoirs of Bazhenov Formation
}

\author{
V.S. Verbitskiy, V.V. Grachev and A.D. Dmitrievskiy
}

\begin{abstract}
Nowadays, the huge amount of the information concerning development and exploitation of hard-to-recover oil has been accumulated. The rational (sustainable) development of the Bazhenov formation is the main target for many years to come. The work is based on the research and has been performed within the framework of the Federal target program with the financial support of the Ministry of Education and Science of the Russian Federation (the unique identifier RFMEFI60714X0080). The aim of the research is to choose the best possible method of oil extraction. During this research, geological aspects of the Bazhenov formation, methods of influence, and field tests results were studied; methods impact on the productive part of the oil deposits; and research based on the extraction of shale oil. As the result of this literature review and patent research, the list of the main methods of influence on Bazhenov formation was formed. Among them, there are hydraulic formation fracturing, thermal methods, gas, and water-gas injection methods. The authors of the research work proposed a new way of development of oil Bazhenov formation, based on the results of mathematical modeling and computational and experimental studies, has created a unique laboratory facility for the integrated modeling of petrophysical and hydrodynamic characteristics of the reservoir model Bazhenov Formation. The project of the technical specification for the installation for vibration stimulation of the formation in the depression mode has been developed.
\end{abstract}

\footnotetext{
V.S. Verbitskiy $(\square)$. V.V. Grachev

Gubkin Russian State University of Oil and Gas

(National Research University), Moscow, Russia

e-mail: vsverbitsky@gmail.com

V.V. Grachev

e-mail: slavamgtu@yandex.ru
}
A.D. Dmitrievskiy
Oil and Gas Institute, Russian Academy of Sciences, Moscow, Russia
e-mail: direction@fcntp.ru


Keywords Scientific and technical solutions - Development of oil fields The Bazhenov formation - Low permeability reservoirs • Fracturing Research • Filtration • Oil reservoir collector • Model • Laboratory installations Vibration exposure

Oil resources in Bazhenov formation, mainly in West Siberia, come to billion tons. Nowadays, there are no industrial methods of oil extraction from Bazhenov formation because of many complicating factors. The productive sediments of Bazhenov formation are source bed and are presented by two lithological reservoir types: Kerogen-clay-chert rocks-bazhenits, usually they present the main thickness of formation; and clayey limestones. Bazhenits can contain hydrocarbons in two substances. First in the form of light low-viscosity oil in voids and second, in the form of kerogen. The usual size of pore is $30-50 \mathrm{~nm}$. Thus, there are collectors with pore sizes nanometers. The collector has an inhomogeneous structure. Therefore, in the Bazhenov formation there are super-permeability layers (super-k). It is well known that super-k leads to a low level of oil recovery due to water breakthrough during the waterflooding period. Thermal methods of development in Bazhenov formation have low oil recovery index (3-5\%) [1, p. 4].

Carrying out hydraulic fracturing in the low-permeable matrix of bazhenits with clay rocks interlayering does not result in any positive effect. In the majority of cases short period of oil production from fractured matrix can be observed after conducted hydraulic fracturing followed by well oil rate decrease to minimum values (below commercial production) and as a result well might be shut in, Pressure maintenance is an option that can extend the period of production from bazhenits. Bazhenits are characterized with the high degree of heterogeneity and include tectonic faults, small shale layers, and that is why injection of gas is preferable for pressure maintenance [2, p. 3].

On the other hand, traditional techniques of pressure maintenance using gas injection cannot provide high ultimate recovery due to the following reasons:

(1) Poor sweep efficiency because of injected gas breakthrough through the super-k layers. It is well-known fact that there is even more negative impact of the heterogeneity on ultimate recovery when low-viscous gas is injected into the reservoir comparing to water injection.

(2) However, injected gas will not interreact with the bazhenits, which contain the main part of hydrocarbon reserves in form of light low-viscosity oil. The same way oil reserves are uncovered with waterflooding because of the breakthrough of water in high permeable fractures.

(3) Laboratory and field studies show that reservoir properties of bazhenits are significantly affected by the reservoir pressure changes. And this is the reason of a huge permeability reduction in the near well-bore area during the production that leads to rate decrease. 
New technology that takes into account all the previous experience of production from bazhenits was created and, in addition unique laboratory facility that allows modeling of different combinations of impact on the bazhenits reservoirs was created.

Suggested technology includes the following: Drilling of horizontal production wells and vertical injection well in accordance with well pattern providing highest ultimate recovery, drilling of additional vertical production wells for creation of wave effects in the near well-bore areas; multistage hydraulic fracturing in the newly drilled wells, including simultaneous wave impact through the additional vertical production wells and injection of fluid into the reservoir (Fig. 1).

Technology includes the sequence of technological operations in alternate cycles, where each cycle consists of three stages: at the first stage fluid is injected into wells for T1 period, what results in reservoir pressure increase, dissolution of liquid hydrocarbons and their release from bound state in the kerogen containing matrix; meanwhile, horizontal producers and vertical injectors are shut in (Fig. 2a); at the second stage, injector and horizontal wells are shut in for the (T2-T1) period. Meanwhile, vertical wells are put into operation in the regime of vibrowave impact without production. Dissolution of liquid hydrocarbons continues and reservoir pressure flattens associated with intensive invasion of injected fluid into the kerogen containing matrix during (T2-T1) period (Fig. 2b). At the third stage, first, horizontal wells are consequently put into operation and after vertical production wells with simultaneous vibrowave impact on the reservoir; meanwhile, injector is shut in for (T3-T2) period (Fig. 2c). Hydrocarbons production continues to the minimum value of reservoir pressure which decreases during production; after that horizontal wells are shut in and vertical wells stop producing hydrocarbons and provide vibrowave impact and injection of fluid starts again (Fig. 2d). T1 period equals to the time necessary to increase reservoir pressure to its initial value, while (T2-T1) period duration is based on the field studies aimed at maximizing oil production from producers till T2 moment of time and T3 corresponds to the time when producing well oil rate reaches the planned minimum value. Produced water and

(a)

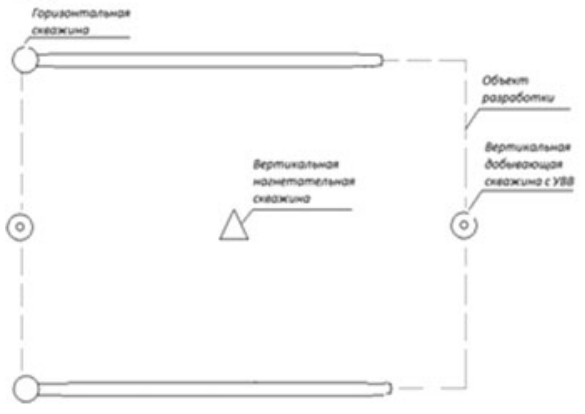

(b)

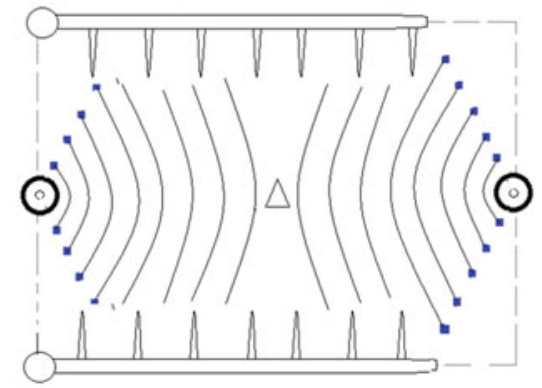

Fig. 1 Stages of preparation object oil field development of the Bazhenov Formation: (a) well drilling, (b) multistage hydraulic formation fracturing 
(a)

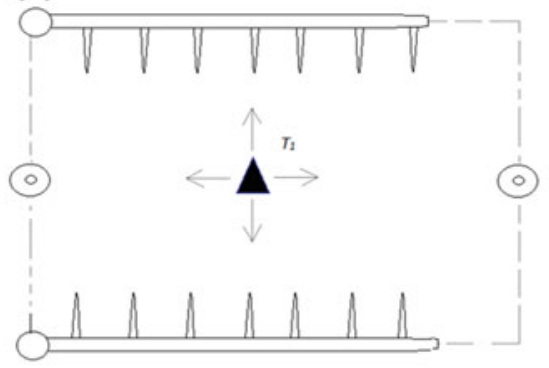

(c)

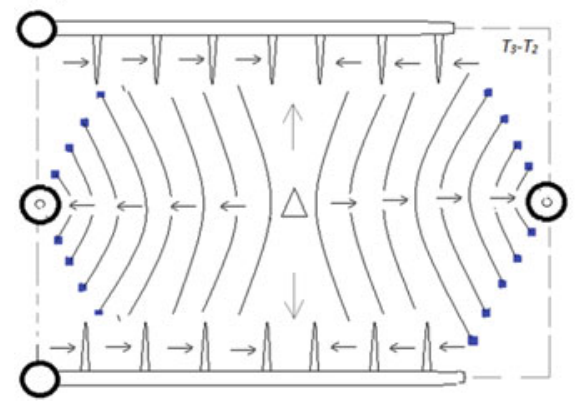

(b)

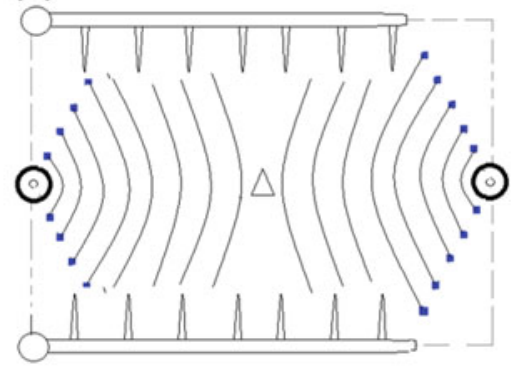

(d)

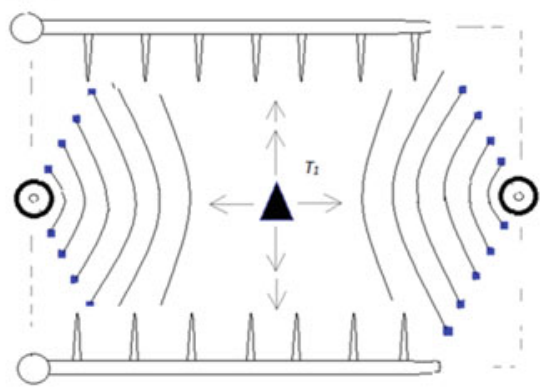

Fig. 2 Realization stages of integral action on reservoir and oil of Bazhenov formation: (a) working fluid injection (producing wells are closed), (b) vibrowave impact with maximum value of bottom hole pressure, (c) producing wells sequence starting, (d) working fluid injection (horizontal wells are closed and vertical are working in circulation pattern)

gas are injected back into the reservoir what results in lower volumes necessary for injection (Fig. 1).

Water injection starts in order to improve sweep efficiency when oil fraction becomes smaller in produced volumes. Water may be considered as a working fluid when polymers are injected in order to improve sweep efficiency. If the considerable amount of swelling clay minerals is present in bazhenits, saline water solutions are used in order to minimize clay swelling, as well as saline water, gel, and polymer solutions, like polyacrylamide water-based solution, and other solutions with increased viscosity might be used. In the case of clay swelling, water alternated gas (WAG) injection with various WAG ratios might be used that maximizes ultimate recovery with minimum impact on the reservoir (WAG ratio selection is based on laboratory studies and results of well testing).

In order to minimize oil production losses due to shut in production wells in case of overpressure, simultaneous operation of producers and injection well as a producer is recommended at the initial period of suggested technology application. Such operation mode continues till the moment when reservoir pressure falls not lower than hydrostatic pressure and production rates reach planned minimum value. 


\section{Conclusions}

Laboratory and 3D simulation model studies are necessary to make the suggested technology widely applied while it is also important to keep static and dynamic models of bazhenits reservoirs updated.

Acknowledgments Research is carried out with the financial support of the state represented by the Ministry of Education and Science of the Russian Federation. Agreement no. 14.607.21.0080, October 20, 2014. Unique project Identifier: RFMEFI60714X0080.

\section{References}

1. Patent 2513963 Russian Federation, 21 B 43/16. The process of development of oil deposits in the sediments of the Bazhenov Formation IPNG RAN the applicant and the patentee: IPNG RAN—№ 2012142692/03; statement: 08.10.2012, published: 20.04.2014, bulletin № 11—9 p. : Illustrations

2. Dmitriyevsky A.N., Dmitriyevsky, A.N., Garifullin, R.I., Karpov, S.N., et al.: Results of complex technology simulation for low-permeable reservoir development. ARPN J. Eng. Appl. Sci. February 2016. 3, 1918-1922 (2016)

Open Access This chapter is licensed under the terms of the Creative Commons Attribution 4.0 International License (http://creativecommons.org/licenses/by/4.0/), which permits use, sharing, adaptation, distribution and reproduction in any medium or format, as long as you give appropriate credit to the original author(s) and the source, provide a link to the Creative Commons license and indicate if changes were made.

The images or other third party material in this chapter are included in the chapter's Creative Commons license, unless indicated otherwise in a credit line to the material. If material is not included in the chapter's Creative Commons license and your intended use is not permitted by statutory regulation or exceeds the permitted use, you will need to obtain permission directly from the copyright holder.

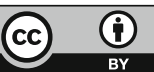

